\section{Patentes farmacêuticas e saúde pública: desafios à política brasileira de acesso ao tratamento anti-retroviral}

\author{
Pharmaceutical patents and public health: \\ challenges for the Brazilian antiretroviral \\ treatment policy
}

Constance Marie Milward de Azevedo

Meiners 1,2

\section{Introdução}

The high prices of patented drugs have fueled the debate regarding the impact of the intellectual property system on access to treatment, with a special focus on HIVIAIDS. The Brazilian policy for antiretroviral treatment, part of a comprehensive program that includes both disease prevention and health promotion activities, has allowed the country to meet goals for coverage and quality and has been considered a model for other countries. However, as the Brazilian STD/AIDS Program reaches maturity, the increasing incorporation of patented drugs into the AIDS treatment regimen imposes an increasing burden on the country's health budget. This article discusses the public health challenges raised by pharmaceutical patents and discusses possible ways to sustain the national policy for free, universal access to HIVIAIDS treatment.

Patents; Pharmaceutical Preparations; Anti-Retroviral Agents
Os direitos de propriedade intelectual passaram por mudanças de grande vulto na década de 1990. Com a assinatura do Acordo sobre Aspectos dos Direitos de Propriedade Intelectual Relacionados ao Comércio (TRIPS), em 1994, e sua gradual internalização pelos países membros da Organização Mundial do Comércio (OMC), nos anos que se seguiram, as patentes sobre produtos e processos farmacêuticos ganharam terreno, tornando-se aplicáveis nos mais diversos contextos econômicos, tecnológicos e sociais. Notavelmente, o momento de intensificação da proteção da propriedade intelectual na esfera global coincidiu com aquele de ampla proliferação da pandemia da AIDS. De cerca de 8 milhões de pessoas infectadas pelo HIV ao redor do mundo em 1990, antes mesmo de finda a década, essa estimativa já ultrapassara os 30 milhões 1 . Tendo em vista o impacto sócio-demográfico e econômico da doença, capaz de atingir dimensões devastadoras nas regiões mais pobres, o tema da AIDS não tardou a ser inserido na agenda internacional, não apenas enquanto uma questão de saúde pública, como também de desenvolvimento humano 2. Face ao custo elevado dos medicamentos utilizados no tratamento contra HIV/AIDS e, conseqüentemente, seu acesso limitado, em um curto espaço de tempo, o regime da propriedade intelectual e o movimento de luta contra o HIV/AIDS entraram em forte colisão. 
O presente artigo tem como objetivo analisar os desafios impostos pelas patentes farmacêuticas à promoção da saúde pública, assim como discutir medidas que viabilizem a continuidade da política brasileira de acesso ao tratamento contra HIV/AIDS. Com vistas a ilustrar o contexto no qual está inserido este debate, o artigo começa por uma exposição sobre a evolução do regime da propriedade intelectual. A próxima seção é dedicada à polêmica entre patentes farmacêuticas e saúde pública e sua repercussão na arena internacional. Na seqüência, após uma apresentação sucinta do Programa Nacional de DST e AIDS (PN DST/AIDS), são abordados os mecanismos que vêm sendo utilizados pelo governo brasileiro para garantir o acesso universal aos medicamentos anti-retrovirais, assim como levantadas respostas aos desafios que se apresentam à sustentação dessa política. Por fim, na conclusão, são feitos breves comentários quanto ao delicado equilíbrio entre a proteção do trabalho intelectual e a promoção da saúde pública e revistas as principais estratégias para garantir o acesso a medicamentos.

\section{O regime da propriedade intelectual}

A propriedade intelectual pode ser definida como um conjunto de direitos atribuídos à atividade criativa. Aplica-se a obras científicas, artísticas e literárias, invenções, marcas, desenhos industriais, programas de computador, entre outros produtos da mente humana. Em termos gerais, divide-se em duas categorias: direitos de autor e propriedade industrial, nas quais estão incluídas as patentes. A patente consiste num privilégio concedido pelo Estado como forma de premiar o esforço inventivo, desde que a inovação apresente novidade em relação ao estado da arte, resulte de atividade inventiva e tenha aplicação industrial 3,4. O titular da patente, ao divulgar socialmente o seu conhecimento, passa a ter direitos exclusivos sobre a produção, uso, venda e importação de seu objeto, por um período limitado, findo o qual o produto ou processo adentra o domínio público.

$\mathrm{O}$ regime internacional da propriedade intelectual tem sua origem a partir de duas convenções: a Convenção da União de Paris para a Proteção da Propriedade Industrial (CUP), de 1883, e a Convenção de Berna para a Proteção de Obras Literárias e Artísticas (CUB), de 1886 4 . No que tange às patentes de invenção, a CUP 5 assume papel fundamental na formação do regime ao estabelecer três princípios chaves: tratamento nacional, prioridade unionista e independência de privilégios. $\mathrm{O}$ tratamento nacional garante a cidadãos ou residentes de qualquer país membro os mesmos direitos concedidos aos cidadãos do país onde se busca a proteção (art. 20). No caso da prioridade unionista, o primeiro a depositar um pedido de patente num país membro da CUP recebe um período de graça de 12 meses para decidir sobre o depósito de seu pedido em qualquer outro país membro, tendo prioridade sobre direitos reclamados por terceiros que, durante esse período, publiquem, explorem ou depositem um pedido referente à mesma invenção (art. 4ô). Por fim, o princípio da independência de privilégios salvaguarda a decisão soberana de cada país sobre a concessão da patente (art. 4bis).

Ao longo do tempo, a CUP passou por seis revisões e uma emenda 6 , tendo sido incorporada, em 1970, ao conjunto de tratados administrados pela recém criada Organização Mundial da Propriedade Intelectual (OMPI) ${ }^{4}$. O reexame periódico da CUP visava à incrementação do regime da propriedade industrial, não sendo sua adesão obrigatória a todos os países membros 3,6. Assim, a CUP permitia a coexistência de diferentes regras aplicáveis a diferentes países, de modo a respeitar as necessidades advindas dos mais diversos níveis de desenvolvimento tecnológico e industrial. Segundo interesses nacionais, cada país pôde definir, internamente, os critérios de patenteabilidade como também os setores passíveis de proteção ${ }^{6}$. Nesse contexto, países como o Brasil e a Índia optaram por excluir proteção ao setor farmacêutico, em vista de seu caráter estratégico e do objetivo de fomentar o processo de estruturação e capacitação da indústria local 7 .

A partir dos anos 1970, teve lugar uma série de mudanças no cenário internacional que contribuiu para deslanchar um processo de reestruturação do regime da propriedade intelectual. O crescimento da economia mundial e o desenvolvimento de bens e serviços intensivos em informação possibilitaram a abertura de mercados competitivos com a presença de novos atores 8 . Beneficiando-se de legislações mais brandas em matéria de propriedade intelectual, países de industrialização recente, por meio de investimentos massivos em engenharia reversa para copiar e adaptar tecnologias, alcançaram posições de destaque no mercado mundial 9,10. Empresas originárias de países desenvolvidos, em especial dos Estados Unidos, alarmadas com a queda em suas vendas, associaram sua perda relativa de competitividade à frágil observância dos direitos de propriedade intelectual 11,12,13,14. Conseqüentemente, os governos desses países passaram a considerar a defesa dos direitos de propriedade intelectual como estratégica nas relações de comércio em vista da necessidade de proteger pesados investimentos em pesquisa $\mathrm{e}$ 
desenvolvimento (P\&D), conter a expansão da indústria da pirataria e assegurar o prestígio de suas empresas.

Nos anos 1980, iniciou-se um movimento pela mudança de fórum do regime da propriedade intelectual. Diante de impasses obtidos no seio da OMPI durante discussões visando ao encrudecimento do regime, assim como da ausência de um mecanismo capaz de efetivamente obrigar o respeito aos direitos de propriedade intelectual, os Estados Unidos, seguidos dos países europeus e do Japão, passaram a imputar sanções bilaterais no comércio com países considerados infratores 9 . Atendendo ao forte lobby das indústrias química, farmacêutica e de informática, esses países mobilizaram-se em prol da inclusão do tema de propriedade intelectual na agenda da Rodada Uruguai (1986-1994) de discussão do Acordo Geral sobre Comércio e Tarifas (GATT) 3,12,13,14. Utilizando como moeda de troca concessões tarifárias nos setores têxtil e agrícola, de particular interesse dos países em desenvolvimento, o grupo de países desenvolvidos colocou em marcha a negociação de um novo tratado multilateral em matéria de propriedade intelectual, logrando impor regras mais rígidas consoante ao padrão que já vigorava em suas leis internas 15 . O TRIPS constituiu assim um dos acordos que integra a Ata Final da Rodada Uruguai, assinada em 1994, que criou a OMC.

O Acordo TRIPS institui padrões mínimos de proteção aos direitos de propriedade intelectual que devem ser obrigatoriamente internalizados pelos países membros da OMC. Ademais, o TRIPS, ao consagrar o vínculo entre propriedade intelectual e comércio, permite fazer uso do mecanismo de solução de controvérsias da OMC (art. 64), como meio de assegurar a observância às suas normas sob ameaça de sanções contra infratores em qualquer área de comércio 16. Estabelece-se, portanto, a base para um regime rígido, amplo e uniforme. As patentes, mais especificamente, estenderam-se a todos os setores tecnológicos, sem possibilidade de discriminação quanto ao fato de os produtos serem importados ou produzidos localmente (art. 27.1), por um período mínimo de vinte anos a contar da data de depósito (art. 33). Dessa forma, os países ficaram impossibilitados de exigir a fabricação local dos produtos patenteados e deixaram de contar com a possibilidade de adequar o grau e o tempo de proteção conferidos segundo suas necessidades de desenvolvimento, como era anteriormente facultado pela CUP.

A única concessão feita com respeito aos diferentes níveis de desenvolvimento sócio-econômico dos países membros diz respeito ao estabe- lecimento de períodos de transição diferenciados (art. 65 e 66). O Acordo TRIPS entrou em vigor em janeiro de 1995, tornando-se obrigatório para os países desenvolvidos um ano depois. Países em desenvolvimento e países de economia centralizada tiveram até o início de 2000 para adaptar suas leis nacionais. Adicionalmente, para países em desenvolvimento que, antes da assinatura do TRIPS, vedavam direitos de propriedade a setores tecnológicos específicos, foi permitido o prazo de até 2005 para estenderem a proteção a esses setores. Países menos desenvolvidos tiveram até 2006 para internalizar o Acordo TRIPS. Já, para os produtos farmacêuticos, o prazo foi estendido até 201617.

Os países desenvolvidos seguiram pressionando pela adesão imediata dos demais países à integralidade do Acordo TRIPS 12,15. No caso do Brasil, antes mesmo da assinatura do Acordo TRIPS, o país vinha sofrendo duras sanções comerciais dos Estados Unidos 18,19,20 em virtude da não-patenteabilidade de produtos e processos farmacêuticos expressa no Código da Propriedade Industrial de 1971 (art. 9o) 21. Em 1996, antes de findo o período de transição, o Brasil acabou por ceder à investida norte-americana e aprovou uma nova Lei da Propriedade Industrial (LPI) 22, que antecipou, para 15 de maio de 1997, a concessão de patentes no setor farmacêutico (art. 243). Além disso, a LPI estabeleceu interinamente um sistema denominado pipeline, permitindo o depósito de pedidos de patentes cujo objeto não tivesse sido colocado em nenhum mercado ou que terceiros não tivessem realizado esforços para sua exploração no Brasil (art. 230 e 231), com privilégios válidos pelo período remanescente da patente concedida no país de origem, não excedendo vinte anos. Assim, não apenas o Brasil abriu mão do período de transição previsto no Acordo TRIPS, como o sistema pipeline possibilitou a proteção de conhecimentos que já se encontravam no domínio público ${ }^{3}$.

Ainda que os países não estejam obrigados a conceder um nível de proteção além do preconizado pelo Acordo TRIPS, discussões visando ao incremento dos direitos de propriedade intelectual têm avançado nos planos regional e bilateral, por meio da inclusão da matéria em acordos de comércio. Esse movimento vem favorecendo a expansão desses direitos a novos campos, bem como a extensão do período de proteção 23,24. As denominadas cláusulas TRIPS plus, presentes em acordos regionais e bilaterais de comércio, restringem, ainda mais, o espaço de manobra para os países em desenvolvimento responderem às demandas políticas internas. À medida que um número maior de países adiram a essas 
cláusulas, maior a tendência de sua incorporação ao regime internacional, cujos impactos para a área de saúde pública, como será discutido mais adiante, merecem cuidados especiais.

\section{Patentes farmacêuticas e saúde pública}

As patentes farmacêuticas encontram-se no centro de uma forte polêmica. De um lado, está o discurso em prol do fortalecimento da indústria farmacêutica que enaltece a importância das patentes para a inovação terapêutica, evocando os ganhos de bem-estar associados a reduções nas taxas de morbidade e mortalidade da população. De outro, a preocupação quanto aos efeitos nocivos relacionados à imposição de barreiras ao acesso a tratamentos mais eficazes e suas conseqüências para a saúde pública.

Ainda que uma relação causal entre patente e inovação não seja de fácil observação, alguns autores (como Arrow, 1962, apud Coriat \& Orsi 11; Gutterman, 1997, apud Correa 25; Granstrand, 1999, apud Correa 25; Le Bas, 1999, apud Correa 25; e Fink \& Primo-Braga 8) afirmam que a falta de recompensa ao esforço inventivo pode levar ao subinvestimento em $\mathrm{P} \& \mathrm{D}$. Na indústria farmacêutica, caracterizada pelo modelo de busca da lucratividade 26 , os investimentos em P\&D têm por objetivo ganhos de competitividade face a produtos estabelecidos no mercado. Considerando-se o alto nível de incerteza envolvido na P\&D de novos fármacos, a ausência de patentes possibilitaria que outras empresas se apropriassem do conhecimento desenvolvido, participando dos lucros na comercialização do produto sem arcar com o ônus de seu desenvolvimento, uma vez que os custos elevados de pesquisa se contrapõem a custos variáveis de produção relativamente baixos 15,27,28. Nesse sentido, a proteção patentária pode ser vista enquanto uma forma de conceder exclusividade à empresa que introduzir produtos inovadores no mercado $29 \mathrm{e}$, portanto, incentivar a atividade inventiva.

Em defesa das patentes farmacêuticas, a Pharmaceutical Research and Manufacturers of America (PhRMA; Estados Unidos) 30 argumenta que o custo médio para o lançamento de um novo medicamento pode atingir 800 milhões de dólares americanos, sendo que todo o processo, desde a descoberta da molécula, a realização de testes pré-clínicos e clínicos à entrada de um medicamento no mercado, pode levar entre 10 e 15 anos. Ademais, alega-se que o índice de perda entre projetos iniciados e medicamentos aprovados para comercialização é alto. Segundo Danzon 31, de cada 10 mil moléculas pesquisadas, cinco passam para a fase de testes clínicos, e apenas uma é comercializada. A incerteza prevalesce também sobre a receptividade do mercado. Um estudo realizado por Grabowski et al. 32 mostra que apenas $30 \%$ dos medicamentos conseguem recuperar o investimento realizado.

Cabe salientar que os dados apresentados pela indústria são objeto de controvérsia. Primeiramente, as empresas farmacêuticas estão entre o grupo de empresas que apresentam índices recordes de lucratividade 26,31,33. Ainda que os riscos envolvidos não devam ser ignorados, alguns autores apontam possíveis exageros. Scherer 29 observa que o tempo dispensado no desenvolvimento de um fármaco pode ser muito menor a dez anos, tendo em vista a associação entre diferentes linhas de pesquisa, o que permite economia de tempo e recursos. Além disso, o cálculo de 800 milhões de dólares anunciado pela indústria ignora a significativa participação de recursos públicos no financiamento da pesquisa farmacêutica 33,34 . No que tange ao abandono de projetos, Luchini et al. 34 explicam que esse fato está relacionado a uma perspectiva ruim de vendas, sendo que as empresas preferem concentrar investimentos em medicamentos que lideram as vendas no mercado (blockbuster drugs) 35 e não obrigatoriamente orientam a pesquisa conforme necessidades identificadas para tratamentos de saúde. Vale notar a ausência de P\&D em doenças raras e tropicais $36,37,38$. Finalmente, não há garantias de que os recursos ganhos com as vendas de medicamentos sejam reinvestidos em P\&D (Love \& Hubbard, 2004, apud Castro \& Westerhaus ${ }^{39}$ ), sendo que as empresas farmacêuticas gastam tanto quanto ou mais a título de publicidade e outros encargos 31,33. Esses argumentos, portanto, lançam dúvidas sobre a relação entre patentes e inovações, de fato, benéficas à sociedade.

Em contrapartida, a exclusividade de mercado 40 , a concentração das vendas a um número reduzido de empresas 27 e a baixa substitutabilidade entre produtos farmacêuticos de diferentes classes terapêuticas 27,37 permitem a prática de preços excessivos. Como a patente farmacêutica veda a entrada de medicamentos genéricos no mercado, durante o período em que vigora a proteção, a concorrência fica limitada à existência de equivalentes terapêuticos. Quando da ausência de substitutos, medicamentos inovadores tendem a apresentar preços elevados 41 . Portanto, dependendo do poder de compra de uma determinada população, assim como do volume do orçamento destinado a programas públicos de saúde, medicamentos essenciais mais caros podem permanecer inacessíveis por um longo período de tempo em detrimento de pessoas que necessitam de tratamento. Evidencia-se, 
portanto, um forte desequilíbrio entre interesses industriais, devidamente protegidos no atual regime da propriedade intelectual, e interesses sociais, como a promoção da saúde pública, que, em vista do preço de medicamentos, encontra-se fortemente fragilizada no caso dos países economicamente desfavorecidos.

Em meados dos anos 1990, a questão do acesso a medicamentos ultrapassou fronteiras, tornando-se objeto de amplo debate na agenda internacional. O lançamento da terapia anti-retroviral altamente ativa (highly active antiretroviral therapy - HAART) no mercado revolucionou o tratamento contra HIV/AIDS, em vista dos excelentes resultados obtidos na redução da mortalidade e morbidade de pacientes. Entretanto, o alto preço dos medicamentos componentes do HAART constituiu uma das principais razões para que milhões de indivíduos permanecessem à margem do tratamento ${ }^{34}$. Uma campanha lançada por ativistas sociais provenientes de diversas organizações não-governamentais 42 , que contou com o envolvimento de políticos, acadêmicos, representantes governamentais, organizações internacionais, personalidades e mídia, logrou engajar a opinião pública internacional na defesa do acesso ao tratamento anti-retroviral enquanto medidas de justiça social e de proteção dos direitos humanos. O Brasil, renomado pelo sucesso do seu programa para HIV/AIDS, participou na defesa dessa causa em inúmeras instâncias internacionais.

$\mathrm{O}$ ano de 2001 representou um importante ponto de inflexão. Presenciou-se uma substancial queda nos preços de medicamentos anti-retrovirais no mercado internacional, com o suprimento de genéricos da Índia 43 , o que possibilitou dar continuidade e estender o tratamento a um número considerável de pessoas vivendo com HIV/AIDS. Dentre eventos marcantes, como o abandono de uma ação judicial movida por 39 empresas farmacêuticas contra o governo da África do Sul 42,44 e de um painel aberto pelos Estados Unidos perante o Órgão de Solução de Controvérsias da OMC contra o Brasil, merece destaque a assinatura da declaração sobre o Acordo TRIPS e saúde pública durante a Quarta Conferência Ministerial da OMC em Doha, Catar. Essa Declaração reconhece a gravidade de problemas de saúde pública a que países em desenvolvimento e menos desenvolvidos estão expostos (\$1) e sua relação com os efeitos que as patentes exercem sobre os preços de medicamentos (\$3o). Afirma que o Acordo TRIPS não previne nem deve prevenir medidas de proteção da saúde pública e o acesso a medicamentos em qualquer circunstância julgada pertinente (\$4으). Parte, assim, da noção de que o uso de flexibili- dades previstas no Acordo TRIPS, notadamente a importação paralela e a licença compulsória (§5o), torna possível o alcance de um equilíbrio entre interesses comerciais e públicos.

Quanto à importação paralela, TRIPS de maneira expressa, não dispõe sobre o assunto (art. 6o). Sua regulamentação fica, portanto, a cargo das legislações nacionais, podendo esse mecanismo ser empregado como instrumento de controle de preços no mercado interno. Cabe notar que a importação paralela não se contrapõe à proteção patentária, uma vez que, quando o produto é colocado em qualquer mercado, os direitos de propriedade se exaurem, tendo em vista que o titular foi recompensado no momento da primeira venda. No que concerne à licença compulsória, suas causas podem ser livremente determinadas, desde que respeitados os dispositivos de TRIPS (art. 31). A licença só pode ser concedida após frustrada a tentativa de obtenção de uma licença voluntária junto ao titular, à exceção dos casos de emergência nacional, de uso público sem fins comerciais ou de abuso de poder econômico. Deve ser temporária, remunerada, não exclusiva e atender, prioritariamente, o mercado interno. Esse último requisito, entretanto, inviabiliza a importação de medicamentos patenteados por países que não dispõem de capacidade de produção farmacêutica local, caso da maioria dos países menos desenvolvidos. A Declaração de Doha determinou que uma solução para esse problema fosse encontrada até o final de 2002 (\$6o). No entanto, apenas em 2003, quando foi acatada a decisão de 30 de agosto pelo Conselho Geral de TRIPS 45, adotada como emenda permanente ao acordo 46 , foi estabelecido um procedimento para a importação de medicamentos sob licença compulsória, bastante criticado por sua complexidade.

A Declaração de Doha, ainda que não apresente concretamente nenhuma alteração ao regime instaurado, tem o efeito de reiterar perante os países desenvolvidos que os demais países não devem ser obrigados a fazer concessões além do que foi disposto em TRIPS. Se o uso das flexibilidades previstas no Acordo é em si suficiente para garantir, de maneira estável e permanente, o acesso a medicamentos é um fator que merece debate. Sobretudo, depende da capacidade tecnológica, do jogo de interesses que influencia o processo de tomada de decisões políticas e do poder de barganha de determinado país onde o problema persiste. As discussões em Doha não ignoraram essa questão. A declaração reitera o compromisso dos países desenvolvidos de incentivar a transferência de tecnologia aos países menos desenvolvidos, conforme disposto no artigo 66.2 de TRIPS (\$7ํo). Porém, a eficácia dessas 
medidas permanece sujeita ao plano das boas intenções.

Se a Declaração de Doha propôs um freio ao enrijecimento do regime da propriedade intelectual, as vias bilateral e regional de negociação, conforme mencionado, têm sido novamente utilizadas como meio de ganhar terreno. No que concerne mais especificamente à saúde pública, são vistas com preocupação cláusulas que estendem o período de proteção conferida pela patente, limitam as condições para a concessão de licenças compulsórias, proíbem o uso de dados de testes clínicos, associam a patente ao registro do medicamento e ampliam a patenteabilidade a novos campos, a usos secundários, a combinações ou partes de produtos já patenteados, a processos análogos 10,23,39. Essas cláusulas permitem proteger conhecimentos que, a rigor, não seriam patenteáveis, em função da ausência de elementos como novidade e atividade inventiva, e tendem a retardar a entrada de genéricos no mercado, fonte estratégica de acesso a tratamentos de saúde mais baratos nos países em desenvolvimento e menos desenvolvidos 34,47,48,49. Diversas organizações não-governamentais, assim como organismos internacionais, em especial a Organização Mundial da Saúde (OMS), têm buscado alertar países para os riscos associados à assinatura de acordos TRIPS plus 23,39,49, o que não necessariamente tem contido a supremacia de interesses agroexportadores por detrás da conclusão desses acordos. O fortalecimento do regime da propriedade intelectual, em detrimento de flexibilidades anteriormente previstas, ameaça colocar em cheque políticas públicas voltadas para o acesso a tratamentos de saúde, sobretudo no caso de países em desenvolvimento e menos desenvolvidos. A seguir, serão considerados os principais desafios à continuidade da política brasileira de tratamento contra HIV/AIDS e o espaço para a ação governamental.

\section{O acesso ao tratamento anti-retroviral no Brasil: estratégias e desafios}

Segundo estimativas do Programa Conjunto das Nações Unidas sobre HIV/AIDS (UNAIDS) 50, existem, no Brasil, cerca de 620 mil pessoas vivendo com HIV/AIDS, o que corresponde a mais de um terço do total de infectados em toda a América Latina. Calcula-se que ocorrem, em média, 11 mil óbitos a cada ano 51, com um acúmulo de aproximadamente 193 mil óbitos notificados entre 1980 e 2006 52. A taxa de prevalência na população entre 15 e 49 anos tem se estabilizado em torno de 0,61\% desde 2000 51. A tendência à estabilização esconde profundas trans- formações no perfil socioeconômico da doença. Embora os grupos mais vulneráveis continuem sendo trabalhadores do sexo, homens que fazem sexo com homens e usuários de drogas injetáveis, em grandes centros urbanos, o HIV/AIDS tem se alastrado de forma preocupante entre mulheres, idosos, na população de baixa renda e no interior 51,53,54.

O PN DST/AIDS foi criado em 1986, em meio ao processo de reforma político-social no Brasil marcado por um movimento organizado da sociedade civil em defesa da saúde como um direito de todos e dever do Estado. Esse direito, reconhecido pela Constituição Federal de 1988 (art. 196), forma a base para a construção do Sistema Único de Saúde (SUS) em 1990 55, cujos princípios incluem o acesso universal, eqüitativo e integral a serviços de saúde (art. 70). O PN DST/ AIDS tem como objetivos conter a transmissão do HIV e promover a saúde de pessoas convivendo com a AIDS. Nesse sentido, desenvolve uma política integrada de prevenção, diagnóstico e tratamento da doença, em que oferece serviços de forma descentralizada, por meio de centros de referência e casas de apoio, capacita profissionais de saúde, apóia a pesquisa e promove a participação social. A política de acesso ao tratamento anti-retroviral tem como referência a Lei $n^{o} .9313 / 1996$ 56, que estabelece a distribuição gratuita, pelo SUS, de medicamentos a todos os portadores de HIV/AIDS que deles necessitem (art. 1o). Essa política cuida tanto da aquisição e distribuição de anti-retrovirais e medicamentos para doenças oportunistas, como também estipula consensos terapêuticos, periodicamente revisados, que almejam a oferta de tratamentos seguros e eficazes.

O PN DST/AIDS distribui 17 anti-retrovirais pelo SUS a aproximadamente 200 mil pacientes 51 . Além do aumento da qualidade de vida e sobrevida dos pacientes em tratamento, a redução em taxas de hospitalização possibilitou uma economia estimada em mais de dois bilhões de dólares americanos até 2006 54. O sucesso do PN DST/AIDS se deve ao emprego de uma combinação de estratégias utilizadas para baratear o custo do tratamento anti-retroviral, de modo a atender objetivos de cobertura em conformidade a critérios de qualidade estabelecidos nos consensos terapêuticos. Em primeiro lugar, a distribuição de preservativos e de conjuntos de agulhas e seringas, além de esforços contínuos de conscientização e mobilização junto a grupos mais vulneráveis e à sociedade em geral, constituem elementos fundamentais para conter novos casos de infecção 53 e, assim, reduzir dramaticamente a demanda por tratamento. Graças às atividades de prevenção, a taxa de incidência da doença re- 
duziu-se significativamente em anos recentes, passando de 22,2 casos por 100 mil habitantes em 2002 para 17,5/100 mil em 2006 52. Adicionalmente, campanhas em torno do diagnóstico precoce prestam importante auxílio à prevenção da doença e, ao mesmo tempo, permitem monitorar pacientes e iniciar o tratamento no momento mais adequado.

Quanto à obtenção de insumos para o tratamento anti-retroviral, merece destaque a exploração da capacidade industrial brasileira para fabricação de medicamentos genéricos e similares, envolvendo laboratórios públicos e privados na produção de oito anti-retrovirais e duas doses combinadas 7,51,53,57. A fabricação local, iniciada em 1993 51, contou com o empreendimento do governo brasileiro e beneficiou-se do fato de que, quando da publicação da LPI em 1996, alguns anti-retrovirais já haviam sido introduzidos no mercado e, portanto, não puderam ter seus pedidos de patente aceitos no Brasil 7. Adicionalmente, vale notar que a produção local de anti-retrovirais contou com a importação de princípios ativos mais baratos provenientes da China e da Índia, países que fizeram jus ao período transitório para aplicação do Acordo TRIPS no setor farmacêutico, o que permitiu diminuir, significativamente, o custo do produto final 43,57. O abastecimento do PN DST/AIDS, a partir de medicamentos genéricos ou similares, certificados pela Agência Nacional de Vigilância Sanitária (ANVISA), permitiu uma importante economia de recursos no orçamento 34,53 .

Outra estratégia importante está relacionada à centralização das compras de anti-retrovirais obtidos junto a laboratórios de origem estrangeira 53. A tomada de uma postura mais agressiva pelo Ministério da Saúde permitiu a obtenção de descontos consideráveis na compra de medicamentos sob proteção patentária. Por três vezes, o país ameaçou utilizar o instrumento da licença compulsória 7: em agosto de 2001, referente ao nelfinavir 51; setembro de 2003, para o efavirenz, nelfinavir e lopinavir/ritonavir (kaletra) 51; e, junho de 2005, para o lopinavir/ritonavir 58. A crença na capacidade de fornecimento de versões genéricas desses medicamentos pela indústria nacional, assim como os custos reais observados na produção dos laboratórios oficiais constituiram fatores cruciais no fechamento de acordos para redução de preços com as empresas farmacêuticas 57. Em maio de 2007, o Brasil decretou o licenciamento compulsório das patentes relacionadas ao efavirenz 59 . O Ministério da Saúde deu início, num primeiro momento, à importação de genéricos da Índia para, oportunamente, dar andamento à produção local desse anti-retroviral.
Em que pese a promulgação da LPI de 1996 ter antecipado em cerca de oito anos a patenteabilidade de produtos e processos farmacêuticos em território brasileiro, assim como ter barrado a importação paralela, ao restringir a exaustão de direitos ao mercado interno (art. 43), exceto no caso de licença compulsória (art. 68), medidas legais mais recentes alinharam-se a uma postura de proteção da saúde pública. Em 1999, foi instituída a anuência prévia da Anvisa à concessão de patentes farmacêuticas (art. 229-C) 60, dispositivo acrescido à LPI em 2001 61. Essa medida, embora sofra duras críticas por parte de agentes da propriedade intelectual e representantes das empresas farmacêuticas transnacionais, viabiliza uma análise mais especializada dos pedidos de patentes na área farmacêutica, tanto em termos de impacto sobre a saúde, quanto de critérios de patenteabilidade e de reprodutibilidade do invento. Permite, portanto, resistir à concessão de privilégios a produtos e processos que, a rigor, não representam avanços terapêuticos, assim como assegurar que o conhecimento a ser protegido possa ser, de fato, transferido à sociedade. Em 2001, foi criado o Grupo Interministerial de Propriedade Intelectual (GIPI) 62, do qual participa o Ministério da Saúde, proporcionando um espaço integrado de discussão da política brasileira de propriedade intelectual. Por fim, em 2003, atendendo a uma demanda do Ministério da Saúde, foi alterado o decreto que regulamenta a licença compulsória nos casos de emergência nacional e interesse público ${ }^{63}$, permitindo agilizar a sua aplicação.

Recentemente, o aumento expressivo nos gastos do PN DST/AIDS começa a apresentar desafios à continuidade da política brasileira de acesso ao tratamento anti-retroviral. Parte desse aumento está relacionado ao próprio sucesso do programa: a expansão da cobertura e a sobrevida dos pacientes. Entre 1997 e 2007, o número de pessoas recebendo tratamento anti-retroviral pelo SUS cresceu em mais de cinco vezes 53 . Ao mesmo tempo, problemas de adesão e resistência ao tratamento geram a necessidade da incorporação de novos fármacos, em geral patenteados ou com pedidos de patente em andamento. Um estudo baseado em dados sobre 188 transações feitas pelo Ministério da Saúde, em nome do PN DST/AIDS, no período entre 1998 e 2002, revelou que, em média, o preço observado dos medicamentos sem proteção patentária são $73,4 \%$ menor que o dos medicamentos patenteados 47 . Assim, conforme cresce a proporção de medicamentos patenteados no tratamento anti-retroviral, o custo médio por paciente tende a aumentar cada vez mais. Em 2000, os anti-retrovirais produzidos localmente ocupavam uma 
posição paritária em comparação aos medicamentos importados. Atualmente, representam menos de $20 \%$ do total de anti-retrovirais consumidos pelo programa ${ }^{53}$. Portanto, a progressiva participação de medicamentos patenteados ou em processo de patenteamento provocou uma ruptura no comportamento de queda do custo médio anual do tratamento por paciente, observado até 2004. Em 2005, esse valor foi quase $70 \%$ superior ao de 2004 53. Caso se mantenha esse ritmo, o aumento expressivo dos gastos com a compra de anti-retrovirais para o programa, num contexto em que os recursos para o atendimento de demandas sociais são escassos, poderá comprometer a política de acesso gratuito e universal ao tratamento contra HIV/AIDS.

Como forma de conter as ameaças à sustentabilidade do PN DST/AIDS, cabe à iniciativa pública lançar mão de medidas que permitam controlar gastos e assegurar a regularidade e qualidade do abastecimento de medicamentos aos pacientes em tratamento. A primeira delas é economizar recursos. A dispensação racional de anti-retrovirais diz respeito à escolha de esquemas terapêuticos que considere a relação entre custo e efetividade, de forma a equacionar princípios de cobertura e qualidade. Nesse sentido, cabe a realização contínua de estudos de avaliação e orientação de profissionais de saúde na adoção de medicamentos que, considerados seus benefícios, tenham, ao longo de todo o tratamento, um custo menor para o SUS. O monitoramento de pacientes, por sua vez, assume papel importante nessa estratégia. Por meio de consultas periódicas e testes de acompanhamento, possibilitam verificar a observância e adesão ao tratamento, ao mesmo tempo que controlar doenças oportunistas, com impacto sobre a redução de hospitalizações. Além disso, os trabalhos de prenvenção e de diagnóstico precoce para combate à disseminação do HIV devem ser intensificados como forma de diminuir a demanda futura por tratamentos.

Outra forma de conter o aumento dos gastos com o tratamento anti-retroviral refere-se a obter uma negociação de preços mais vantajosa junto aos laboratórios farmacêuticos. A incorporação do mecanismo de importação paralela poderia vir a atender esse propósito, uma vez que, ao criar alternativas de fornecimento por meio de outros mercados, concederia maior poder de barganha ao governo. Essa medida, no entanto, depende de um trabalho de mobilização política em torno da revisão da LPI. Outro instrumento de negociação, a ameaça de licenciamento compulsório, tem, de modo geral, melhorado as condições de fornecimento de medicamentos ao Ministério da Saúde. Mas, para que essa ameaça continue sur- tindo efeito, não devem restar dúvidas quanto ao potencial do país de levá-la a cabo. Até o momento, o Brasil tem contado fortemente com o suprimento de princípios ativos da Índia e, em menor escala, da China para atender as necessidades da produção de genéricos. Essa situação traz consigo dois problemas. Primeiramente, coloca em dúvida a capacidade da indústria farmacêutica local de realizar a síntese de matéria-prima 7,37,53. Em segundo lugar, o constante recurso a importações tende a desmobilizar a indústria local e acirrar a dependência de princípios ativos provenientes de fontes externas 64 .

A dependência em termos de matéria-prima farmacêutica, que representa cerca de $65 \%$ do custo do produto final, tende a colocar o Brasil em forte desvantagem e reduzir sensivelmente seu poder de barganha na negociação de novos contratos para fornecimento de anti-retrovirais. Deve-se considerar que, com a expansão do acesso ao tratamento contra HIV/AIDS nos países menos desenvolvidos, fruto da campanha internacional de acesso a anti-retrovirais, existe a possibilidade de escassez e, conseqüentemente, de encarecimento dos princípios ativos 65. Mais preocupante ainda, a recente internalização da proteção patentária para o setor farmacêutico nas legislações de propriedade intelectual da China e da Îndia implica, no médio prazo, sérias barreiras ao fornecimento de insumos para novos medicamentos. Nesse contexto, com vistas a evitar que o país fique à mercê de laboratórios estrangeiros, a aquisição de capacidade tecnológica, sobretudo na síntese de princípios ativos, constitui peça fundamental para garantir autonomia na política de acesso ao tratamento anti-retroviral, podendo, inclusive, gerar benefícios para outros programas públicos de dispensação farmacêutica. O uso efetivo do licenciamento compulsório, aliado ao esforço de engenharia reversa, pode ser um dos meios utilizados. Porém, dado que o recurso à licença compulsória tende a ser intermitente, não apresenta garantias de um processo de aprendizado continuado. Portanto, o Brasil deve insistir na via do licenciamento voluntário de forma a obter a transferência direta de conhecimento a laboratórios detentores de direitos patentários.

Além do emprego de recursos públicos diretos em P\&D, uma das medidas auxiliares ao objetivo de capacitação tecnológica trata da revisão da política de compras governamentais de insumos farmacêuticos, de modo a incentivar a participação do setor privado 64 . $\mathrm{O}$ apoio à produção de medicamentos genéricos de qualidade tratase de uma medida importante para manter ativa a produção interna. Ao mesmo tempo, esforços devem ser concentrados não apenas na repro- 
dução de medicamentos, mas na pesquisa em tratamentos de interesse local, muitas vezes negligenciados pelos grandes laboratórios farmacêuticos transnacionais. Nesse aspecto, ganham importância políticas direcionadas à especialização de recursos humanos, ao estabelecimento de parcerias com o setor privado e à cooperação científica e tecnológica com países de interesses e níveis de desenvolvimento industrial comparáveis ao do Brasil, que devem ser mantidas e estimuladas. Por fim e não menos importante, o rigor na análise de pedidos de patentes, assim como a resistência à incorporação de cláusulas TRIPS plus são medidas essenciais para facilitar o acesso a tratamentos de saúde, uma vez que visam evitar a proteção de fármacos não inovadores, garantir a reprodutibilidade de processos inventivos, cruciais nos casos de licenciamento compulsório, assim como assegurar a entrada imediata de genéricos no mercado após esgotada a proteção patentária.

\section{Considerações finais}

O regime da propriedade intelectual tem avançado no sentido de ampliar, cada vez mais, os direitos dos detentores de tecnologia. O enrijecimento desses direitos têm, direta ou indiretamente, comprometido a consecução de políticas sociais. O impacto da proteção patentária sobre o preço dos anti-retrovirais constitui uma barreira significativa ao acesso ao tratamento de HIV/AIDS nos países em desenvolvimento. Até recentemente, o governo brasileiro conseguiu lançar mão de estratégias que permitiram sustentar um programa universal e de qualidade, que se tornou referência no mundo.

O Brasil contou com um cenário internacional favorável. A disponibilidade de fontes alternativas de matéria-prima para a produção mais barata de medicamentos e a mobilização da opinião pública internacional permitiram fazer face às investidas ambiciosas da indústria farmacêutica. Adicionalmente, o país soube fazer uso da capacidade industrial instalada para produzir genéricos e similares de qualidade, assim como utilizou, com astúcia, as flexibilidades previstas no Acordo TRIPS para negociar o fornecimento de anti-retrovirais de marca a preços reduzidos. A substancial queda do custo médio anual por paciente em tratamento, observada a partir do ano 2000, tem beneficiado outros países onde vêm sendo implantados programas de acesso ao tratamento anti-retroviral 48 .
$\mathrm{O}$ ano 2005 marca um novo período. O aumento expressivo do custo médio anual por paciente, se mantido, desafia a capacidade de finaciamento do PN DST/AIDS. Mudanças recentes nas legislações de propriedade intelectual nos países provedores de princípios ativos e a anunciada escassez de matéria-prima para suprir a crescente demanda internacional desenham um cenário pouco encorajador a médio prazo. Medidas precisam ser tomadas no sentido de reverter a tendência de aumento excessivo dos gastos do Programa e garantir a sustentabilidade da política de acesso universal e gratuito ao tratamento contra HIV/AIDS. O Brasil acaba de conceder, pela primeira vez, a licença compulsória sobre as patentes de um anti-retroviral responsável por um consumo considerável do orçamento para medicamentos do PN DST/AIDS. Resta observar até que ponto será capaz de concentrar esforços no domínio da fabricação completa desse fármaco de forma a reduzir a dependência externa em insumos farmacêuticos.

Os desafios que começam a ser enfrentados pelo caso brasileiro dão um claro sinal de que o conflito entre patentes farmacêuticas e acesso a medicamentos não se esgotou e ameaça outros países à medida que seus programas amadureçam. O uso das flexibilidades do Acordo TRIPS é a recomendação que vem sido persistentemente feita aos governos. Para tanto, exige um número de cuidados. Dentre os quais, está em implementar maior rigor no exame de patentes e resistir a pressões em torno da adoção de cláusulas TRIPS plus. Além disso, cabe trazer à tona discussões sobre a inclusão do mecanismo de importação paralela na legislação brasileira como instrumento para melhorar o poder de barganha do governo nas negociações com os laboratórios detentores de direitos patentários. Outro fator essencial diz respeito à autonomia na produção de fármacos. No Brasil, há muito se discute a necessidade de investir no desenvolvimento da indústria farmacêutica, tanto no que diz respeito à engenharia inversa quanto à capacidade inovadora. Não se trata apenas de um problema de recursos, grande parte se deve à falta de integração de políticas e de gestão inadequada desses recursos. Portanto, além de investimento em P\&D e recursos humanos e do fomento à cooperação internacional, faz-se necessária a revisão de incentivos à participação do setor privado. Por fim, a prescrição racional de esquemas terapêuticos e a expansão das políticas de prevenção e diagnóstico do PN DST/AIDS têm a contribuir para a redução de custos do programa. 


\section{Resumo}

O preço elevado de medicamentos patenteados tem intensificado o debate em torno do impacto do regime da propriedade intelectual sobre o acesso a tratamentos de saúde, merecendo destaque o caso do HIVIAIDS. A política brasileira de tratamento anti-retroviral, parte de um programa nacional que integra medidas de prevenção e promoção da saúde, permitiu o alcance de uma ampla cobertura com qualidade, tendo sido apontada como modelo para outros países. Não obstante, conforme amadurece o Programa Nacional de DST e AIDS, os gastos com a incorporação de anti-re- trovirais patenteados ao esquema terapêutico para pacientes em tratamento atinge um peso, cada vez maior, em seu orçamento. O presente artigo toma em conta os desafios apresentados pelas patentes farmacêuticas à saúde pública e discute possíveis caminhos para a sustentação da política de acesso universal e gratuito ao tratamento contra HIVIAIDS no Brasil.

Patentes; Preparações Farmacêuticas; Anti-Retrovirais

\section{Referências}

1. Avert. AIDS timeline. http://www.avert.org/aids -timeline.htm (acessado em 31/Out/2007).

2. Joint United Nations Programme on HIV/AIDS. 2006 Report on the global AIDS epidemic: Geneva: Joint United Nations Programme on HIV/AIDS; 2006

3. Barbosa ALF. Sobre a propriedade do trabalho intelectual: uma perspectiva crítica. Rio de Janeiro: Universidade Federal do Rio de Janeiro; 1999.

4. World Intellectual Property Organization. WIPO intellectual property handbook. 2nd Ed. Geneva: World Intellectual Property Organization; 2004.

5. Paris Convention for the Protection of Industrial Property. http://www.wipo.int/treaties/en/ip/par is/trtdocs_wo020.html.

6. Bodenhausen GHC. Guide to the application of the Paris Convention for the Protection of Industrial Property as revised at Stockholm in 1967. Geneva: World Intellectual Property Organization; 1991.

7. Cassier M, Correa M. Propriedade intelectual e saúde pública: a cópia de medicamentos contra HIV/Aids realizada por laboratórios farmacêuticos brasileiros públicos e privados. Revista Eletrônica de Comunicação, Informação \& Inovação em Saúde 2007; 1:83-91.

8. Fink C, Primo-Braga CA. How stronger protection of intellectual property rights affects international trade flows. Washington DC: International Bank for Reconstruction and Development; 1999. (Working Paper, 2051).
9. Kim L, Nelson RR, organizadores. Tecnologia, aprendizado e inovação: as experiências das economias de industrialização recente. Campinas: Editora da Unicamp; 2005.

10. Chaves GC, Oliveira MA, Hasenclever L, Melo LM A evolução do sistema internacional de propriedade intelectual: proteção patentária para o setor farmacêutico e acesso a medicamentos. Cad Saúde Pública 2007; 23:257-67.

11. Coriat B, Orsi F. Establishing a new intellectual property rights regime in the United States: origins, content and problems. Research Policy 2002; 31:1491-507.

12. Correa CM. Intellectual property rights, the WTO and developing countries: the TRIPS agreement and policy options. Penang: Third World Network; 2000.

13. Rêgo ECL. Acordo sobre propriedade intelectual na OMC: implicações para a saúde pública nos países em desenvolvimento. Revista do BNDES 2001; 8:43-78.

14. Roffe P. La propiedad intelectual y el comercio internacional: las negociaciones multilaterales en el GATT. Integración Latinoamericana 1989; 14:24-31.

15. Scherer FM. The pharmaceutical industry and world intellectual property standards. Vanderbilt Law Rev 2000; 53:2245-54. 
16. World Trade Organization. Agreement on trade-related aspects of intellectual property rights. http:// www.wto.org/english/docs_e/legal_e/27-trips. pdf.

17. World Trade Organization. Declaration on the trips agreement and public health. http://www.wto. org/english/thewto_e/minist_e/min01_e/minde cl_trips_e.pdf.

18. Albuquerque EM. Sistemas nacionais de inovação e direitos de propriedade industrial: notas introdutórias sobre um debate necessário. Estudos Econômicos 1996; 26:141-304.

19. Barbieri JC. Sistemas nacionais de inovação e direitos de propriedade industrial: notas introdutórias sobre um debate necessário. Rev Adm Pública 2001; 35:107-29.

20. Varella MD. L'Organisation Mondiale du Commerce, les brevets, les médicaments et le rapport Nord-Sud: un point du vue du Sud. Revue Internationale de Droit Economique 2004; 18:79-117.

21. Brasil. Lei no ${ }^{\circ}$ 5.772. Institui o Código da Propriedade Industrial e dá outras providências. Diário Oficial da União 1971; 21 dez.

22. Brasil. Lei $n^{\circ}$. 9.279. Regula direitos e obrigações relativos à propriedade industrial. Diário Oficial da União 1996; 14 mai.

23. Krikorian G. L'accès aus génériques. Enjeux actuels e propriété intellectuelle. Paris: AIDES; 2005.

24. Velasquez G. Bilateral trade agreements and access to essential drugs. In: Bermudez JAZ, Oliveira MA, editors. Intellectual property in the context of the WTO TRIPS agreement: challenges for public health. Rio de Janeiro: Escola Nacional de Saúde Pública, Fundação Oswaldo Cruz; 2004. p. 63-70.

25. Correa CM. Trends in drug patenting: case studies. Buenos Aires: Corregidor; 2001.

26. Scherer FM. The link between gross profitability and pharmaceutical R\&D spending. Health Aff 2001; 20:216-20.

27. Berndt ER. Pharmaceuticals in U.S. healthcare: determinants of quantity and price. Journal of Economics Perspectives 2002; 16:45-66.

28. Giaccotto C, Santerre RE, Vernon JA. Drug prices and research and development investment behavior in the pharmaceutical industry. J Law Econ 2005; 48:195-214.

29. Scherer FM. The pharmaceutical industry: prices and progress. N Engl J Med 2004; 351:927-32.

30. The Pharmaceutical Research and Manufacturers of America. Drug discovery and development: understanding the R\&D process. http://www.phrma. org/files/RD\%20Brochure\%20022307.pdf (acessado em 15/Nov/2007).

31. Danzon P. The pharmaceutical industry. In: Bouckaert B, Geest GD, editors. The encyclopedia of law and economics. Northampton: Edward Elgar; 2000. p. 1055-91.

32. Grabowski H, Vernon J, DiMasi J. Returns on R\&D for 1990s new drug introductions. http://www. dklevine.com/archive/grabow-randd_returns.pdf (acessado em 15/Ago/2005).
33. Barros J. Políticas farmacêuticas: a serviço dos interesses da saúde? Brasília: Organização das Nações Unidas para a Educação, a Ciência e a Cultura/Agência Nacional de Vigilância Sanitária; 2004.

34. Luchini S, Cisse B, Duran S, Cenival M, Comiti C, Gaudry M, et al. Decrease in prices of antiretroviral drugs for developing countries: from political "philantropy» to regulated markets? In: Moatti JP, Coriat B, Souteyrand Y, Barnett T, Dumoulin J, Flori YA, editors. Economics of AIDS and access to HIV/ AIDS care in developing countries issues and challenges. Paris: Agence Nationale de Recherches sur le Sida et les Hépatites Virales; 2003. p. 169-211.

35. Pajot G. The pharmaceutical market at a crossroad. Presentation for Europe and Africa. IMS Health; 2003; http://www.pharmaceutiques.com/phq/ colloques/univ_2003/20030913_pajot.pdf (acessado em Ago/2005).

36. Lanjouw JO, Cockburn I. Do patents matter? Empirical evidence after GATT. Cambridge: National Bureau of Economic Research; 2000. (NBER Working Paper, 7495).

37. Oliveira EA, Labra ME, Bermudez J. A produção pública de medicamentos no Brasil: uma visão geral. Cad Saúde Pública 2006; 22:2379-89.

38. Scherer FM. Global welfare in pharmaceutical patenting. http://www.iipi.org/Conferences/IP\& Health/scherer_paper.pdf (acessado em 18/Ago/ 2005).

39. Castro A, Westerhaus M. Access to generic antiretrovirals: inequality, intellectual property law, and international trade agreements. Cad Saúde Pública 2007; 23 Suppl 1:S85-96.

40. Penrose ET. La economía del sistema internacional de patentes. México DF: Siglo XXI; 1974.

41. Lu J, Comanor W. Strategic pricing of new pharmaceuticals. Rev Econ Stat 1998; 80:108-18.

42. Galvão J. A política brasileira de distribuição e produção de medicamentos anti-retrovirais: privilégio ou um direito? Cad Saúde Pública 2002; 18:213-9.

43. Orsi F, D'Almeida C, Hasenclever L, Camara M, Tigre P, Coriat B. TRIPS post-2005 and access to new antiretroviral treatments in southern countries: issues and challenges. AIDS 2007; 21:1997-2003.

44. 't Hoen E. TRIPS, pharmaceutical patents and access to essential medicines: Seattle, Doha and beyond. In: Moatti JP, Coriat B, Souteyrand Y, Barnett T, Dumoulin J, Flori YA, editors. Economics of AIDS and access to HIV/AIDS care in developing countries Issues and Challenges. Paris: Agence Nationale de Recherches sur le Sida et les Hépatites Virales; 2003. p. 39-67.

45. World Trade Organization. Implementation of paragraph 6 of the Doha Declaration on the TRIPS Agreement and public health. http://www.wto.org/ english/tratop_e/trips_e/implem_para6_e.htm.

46. World Trade Organization. Amendment of the TRIPS agreement. http://www.wto.org/english/ tratop_e/trips_e/wtl641_e.htm.

47. Meiners CMMA. Pharmaceutical patents and access to HIV/AIDS treatment: the Brazilian experience [Dissertação de Mestrado]. York: University of York; 2005. 
48. Coriat B, Orsi F, d'Almeida C. TRIPS and the international public health controversies: issues and challenges. Industrial and Corporate Change 2006; 15:1033-62.

49. Organización Panamericana de la Salud/Organización Mundial de la Salud. Los aspectos de los derechos de propiedad intelectual relacionados con el comercio (ADPIC) y el acceso a medicamentos. Informe del Grupo de Trabajo. Santo Domingo: Organización Panamericana de la Salud/Organización Mundial de la Salud; 2005.

50. World Health Organisation, Joint United Nations Programme on HIV/AIDS. Epidemiological fact sheets on HIV/AIDS and sexually transmitted diseases: Brazil 2006 update. Geneva: World Health Organisation, Joint United Nations Programme on HIV/AIDS; 2006.

51. Programa Nacional para DST e AIDS, Ministério da Saúde. Epidemiologia. http://www.aids.gov.br/ (acessado em 15/Nov/2007).

52. Ministério da Saúde. Boletim epidemiológico DST AIDS 2007; iv(1).

53. Greco DB, Simão M. Brazilian policy of universal access to AIDS treatment: sustainaility, challenges and perspectives. AIDS 2007; 21:34-45.

54. Okie S. Fighting HIV. Lessons from Brazil. N Engl J Med 2006; 354:1977-81.

55. Brasil. Lei no ${ }^{\circ}$ 8.080, de 19 de setembro de 1990. Dispõe sobre as condições para a promoção, proteção e recuperação da saúde, a organização e o funcionamento dos serviços correspondentes e dá outras providências. Diário Oficial da União 1990; 20 set.

56. Brasil. Lei $n^{\circ}$. 9.313. Dispõe sobre a distribuição gratuita de medicamentos aos portadores do HIV e doentes de AIDS. Diário Oficial da União 1996; 13 nov.

57. Orsi F, Hasenclever L, Fialho B, Tigre P, Coriat B. Intellectual property rights, anti-AIDS policy and generic drugs: lessons from the Brazilian public health program. In: Moatti JP, Coriat B, Souteyrand Y, Barnett T, Dumoulin J, Flori YA, editors. Economics of AIDS and access to HIV/AIDS care in developing countries Issues and challenges. Paris: Agence Nationale de Recherches sur le Sida et les Hépatites Virales; 2003. p. 109-35.
58. Brasil. Portaria no. 985/MS/GM. Declara, para fins de sustentabilidade social do programa brasileiro de combate à AIDS, interesse público relativamente aos medicamentos advindos da associação dos princípios ativos Lopinavir e Ritonavir, com vistas à composição do rol dos inibidores de protease que devem compor o arsenal terapêutico para o tratamento da infecção por HIV/AIDS no Brasil. Diário Oficial da União 2005; 24 jun.

59. Brasil. Decreto $n^{\circ}$. 6.108. Concede licenciamento compulsório, por interesse público, de patentes referentes ao Efavirenz, para fins de uso público não-comercial. Diário Oficial da União 2007; 4 mai.

60. Brasil. Medida Provisória nº 2.006. Altera e acresce dispositivos à Lei no ${ }^{\circ}$ 9.279, de 14 de maio de 1996, que regula direitos e obrigações relativos à propriedade industrial, e dá outras providências. Diário Oficial da União 1999; 14 dez.

61. Brasil. Lei $n^{\circ}$. 10.196. Altera e acresce dispositivos à Lei no. 9.279, de 14 de maio de 1996, que regula direitos e obrigações relativos à propriedade industrial, e dá outras providências. Diário Oficial da União 2001; 14 fev.

62. Brasil. Decreto de 21 de Agosto de 2001. Cria, no âmbito da CAMEX - Câmara de Comércio Exterior, o Grupo Interministerial de Propriedade Intelectual, disciplina sua composição e funcionamento, e dá outras providências. Diário Oficial da União 2001; 21 ago.

63. Brasil. Decreto $\mathrm{n}^{\circ}$. 4.830. Dá nova redação aos arts. 1o, 2o, 5o, 9o e 10o do Decreto no. 3.201, de 6 de outubro de 1999, que dispõe sobre a concessão, de ofício, de licença compulsória nos casos de emergência nacional e de interesse público de que trata o art. 71 da Lei no. 9.279, de 14 de maio de 1996. Diário Oficial da União 2003; 4 set.

64. Quental C, Abreu JC, Bomtempo JV, Gadelha CAG. Medicamentos genéricos no Brasil: impactos das políticas públicas sobre a indústria nacional. Ciênc Saúde Coletiva 2008; 13 Suppl:619-28.

65. Pinheiro E, Vasanb A, Kimb JY, Evan L, Guimierd JM, Perriensa J. Examining the production costs of antiretroviral drugs. AIDS 2006; 20:1745-52.

Recebido em 19/Jun/2007

Versão final reapresentada em 18/Mar/2008

Aprovado em 19/Mar/2008 